\title{
Patentes e espaço geográfico: Uma análise espacial do território piauiense
}

\section{Patents and geographical space: A spatial analysis of the territory of Piauí}

\section{Patentes y espacio geográfico: Un análisis espacial del territorio de Piauí}

Robson Almeida Borges de Freitas

ORCID: https://orcid.org/0000-0002-5888-6022 Instituto Federal de Educação, Ciência e Tecnologia do Piauí, Brasil E-mail: robson.freitas@ifpi.edu.br

Antonio Martins de Oliveira Junior

ORCID: https://orcid.org/0000-0002-8635-7048 Universidade Federal de Sergipe, Brasil E-mail:amartins.junior@gmail.com

Paulo Henrique de Carvalho Bueno ORCID: https://orcid.org/0000-0003-3118-3834 Instituto Federal de Educação, Ciência e Tecnologia do Piauí, Brasil E-mail: paulo.bueno@ifpi.edu.br

Márcio Aurélio Carvalho de Morais ORCID: https://orcid.org/0000-0001-6626-1615 Instituto Federal de Educação, Ciência e Tecnologia do Piauí, Brasil E-mail: marcio@ifpi.edu.br

Humbérila da Costa e Silva Melo

ORCID: https://orcid.org/0000-0002-8923-3235 Instituto Federal de Educação, Ciência e Tecnologia do Piauí, Brasil E-mail: humberila@ifpi.edu.br

Daniel Leite Viana Costa

ORCID: https://orcid.org/0000-0003-4651-0906 Instituto Federal de Educação, Ciência e Tecnologia do Piaú, Brasil E-mail: daniel.leite@ifpi.edu.br

\begin{abstract}
Resumo
As Instituições Públicas de Pesquisa (IPP) possuem missões definidas em lei para com a sociedade. O artigo objetivase a analisar a espacialidade da produção de patentes das IPP. Para tanto, relacionou-se os territórios de desenvolvimento do estado do Piauí e sua vocações econômicas com base na literatura e em órgãos governamentais. Para as patentes, buscou-se os documentos de tecnologias desenvolvidas pelas IPP do Piauí e analisou-se seus títulos e resumos. Foram encontradas 98 patentes, das quais 39 relacionam-se com as vocações econômicas dos piauienses e seus recursos. Um total de 160 interações foi identificado com destaque para a agroindústria e para a apicultura. Os territórios Entre Rios e Cocais possuem o maior número de relações, no entanto, quando soma-se as relações presentes na região do semiárido, nota-se a maior concentração (85). Com isso, considera-se as interações entre os territórios de desenvolvimento e a produção tecnológica crucial para melhoria de vida das pessoas, embora seja necessário promover a chegada dessas tecnologias para os arranjos sociais e produtivos por meio de Transferência de Tecnologias.

Palavras-chave: Instituições públicas de pesquisa; Desenvolvimento territorial; Patentes; Piauí.

Abstract

Public Research Institutions (PRI) have missions defined by law for society. The article aims to analyze the spatiality of PRI patent production. Therefore, the development territories of the state of Piauí and their economic vocations were related based on literature and government agencies. For patents, the documents of technologies developed by those in Piauí were searched and their titles and abstracts were analyzed. 98 patents were found, 39 of which relate to the economic vocations of Piauí and their resources. A total of 160 interactions were identified, with emphasis on agroindustry and beekeeping. The territories Entre Rios and Cocais have the highest number of relationships, however, when the relationships in the semiarid region are added, the highest concentration is observed (85). Thus, the interactions between development territories and technological production are considered crucial for improving people's lives, although it is necessary to promote the arrival of these technologies for social and productive arrangements through Technology Transfer.
\end{abstract}

Keywords: Public research institutions; Territorial development; Patents; Piauí. 


\begin{abstract}
Resumen
Las Instituciones Públicas de Investigación (IPI) tienen misiones definidas por ley para la sociedad. El artículo tiene como objetivo analizar la espacialidad de la producción de patentes IPI. Por tanto, los territorios de desarrollo del estado de Piauí y sus vocaciones económicas se relacionaron a partir de la literatura y las agencias gubernamentales. Para las patentes, se buscaron los documentos de tecnologías desarrolladas por los de Piauí y se analizaron sus títulos y resúmenes. Se encontraron 98 patentes, 39 de las cuales se relacionan con las vocaciones económicas de Piauí y sus recursos. Se identificaron un total de 160 interacciones, con énfasis en la agroindustria y la apicultura. Los territorios Entre Ríos y Cocais tienen el mayor número de relaciones, sin embargo, cuando se suman las relaciones en la región semiárida, se observa la mayor concentración (85). Así, las interacciones entre territorios de desarrollo y producción tecnológica se consideran cruciales para mejorar la vida de las personas, aunque es necesario promover la llegada de estas tecnologías para arreglos sociales y productivos a través de la Transferencia de Tecnología.
\end{abstract}

Palabras clave: Instituciones públicas de investigación; Desarrollo territorial; Patentes; Piauí.

\title{
1. Introdução
}

As Instituições Públicas de Pesquisa (IPP) possuem missões estabelecidas em lei para com a sociedade. Para além das certificações de saberes e competências, possui a finalidade de promover pesquisas e desenvolvimento tecnológico. Ainda dentro do escopo legislativo, observa-se que as IPP devem promover a Transferência de Tecnologias para os arranjos sociais e produtivos (Lei no 9.394, 1996; Decreto n. 2.207, 1997; Decreto n. 5.154, 2004; Lei no. 11.892, 2008). A lei No 10.973 de 2 de dezembro de 2004 trata sobre as pesquisas, o desenvolvimento tecnológico, a inovação e o alcance dos arranjos produtivos e sociais. A lei dispõe sobre os Núcleos de Inovação Tecnológica (NIT) e suas competências com o desenvolvimento tecnológico e sua transferência.

Os debates sobre a estruturação e cumprimento das funções dos NIT são presentes na literatura e nos relatórios de gestão do Ministério da Ciência, Tecnologia, Inovações e Comunicações (Livesey,2014; Ministério da Ciência, Tecnologia e Inovação, 2019). No entanto, as dificuldades encontradas no processo de Transferência de Tecnologias possuem matizes, uma vez que muitas patentes permanecem dentro das instituições e não alcançam o mercado produtivo, situação que gera problemas de gestão de portfólios tecnológicos, manutenção de patentes e de investimento em áreas promissoras (Garnica, 2006; Brito e Fausto, 2015; Soares, 2018; De Almeida, 2019; De Oliveira Junior e De Almeida, 2019; Freitas, De Oliveira Júnior, Melo, Azevedo e Silva, 2020).

Nesse sentido, objetiva-se analisar a espacialização das patentes desenvolvidas pelas Instituições Públicas de Pesquisas piauienses pelos seus territórios de desenvolvimento. Argumenta-se que os territórios com maiores dinâmicas econômicas são os que mais possuem registros de inovações tecnológicas, as quais atrelam-se aos potenciais produtivos locais. Com efeito, examinar as patentes relacionadas com os arranjos econômicos ativos e em desenvolvimento, e nas oportunidades geradas com essa relação, torna-se relevante e justifica a incursão. Com a compreensão do entorno das IPP pode-se alinhar esforços governamentais, institucionais e empresariais.

No contexto territorial do estado do Piauí, encontra-se na literatura algumas áreas de exploração econômica relacionada com sua espacialidade. Dentro do espaço geográfico piauiense, o povo e a economia a que estão inseridos encontram suas vocações (Façanha, 2009; Gândara, 2013; Carvalho, 2015; Putrick, 2019; Santos, 2020). Nesse sentido, os esforços dos Arranjos Produtivos Locais representados pelas APL presentes nas regiões do Piauí possuem forte influência no desenvolvimento endógeno. Isso deve-se à organização cooperativa, com ou sem apoio governamental, que promove a relação entre atores sociais para fortalecimento de atividades produtivas.

A Secretaria de Planejamento do Estado (SEPLAN) aponta 12 territórios de desenvolvimentos no estado do Piauí. São eles: Carnaubais, Chapada das Mangabeiras, Chapada Vale do Rio Itaim, Cocais, Entre Rios, Planície Litorânea, Serra da Capivara, Tabuleiros do Alto Parnaíba, Vale do Rio Canindé, Vale do Guaribas, Vale dos Rios Piauí e Itaueira, Vale do Sambito. Gândara (2013) concede um estudo sobre o território do Vale do Guaribas, atualmente também dividido em Vale do Itaim. O autor trata das vocações em cajucultura e apicultura da região e suas dinâmicas no uso da terra. Já Carvalho (2015) 
apresenta sua análise sobre os APL do território Cocais, especificamente na região de Pedro II com a fonte principal na mineração de opala e no turismo gerado na região. Corroborando com a vocação pelo turismo na região Cocais, Façanha (2009) relata sobre a vocação para a arqueologia e seu turismo na região, em que Putrick (2019) enfoca na "Rota das Emoções" e o desenvolvimento gerado nos entornos.

Santos (2020) apresenta mudanças recentes na dinâmica dos serviços de saúde no Piauí. O Quadro 1 mostra algumas dinâmicas econômicas do estado do Piaú, e a Figura 1 apresenta o mapa dos territórios disponibilizado pela SEPLAN.

Quadro 1: Dinâmicas econômicas relevantes no Piauí.

\begin{tabular}{|l|l|}
\hline Vertente Econômica & Território de desenvolvimento em destaque \\
\hline Apicultura & Vale do Guaribas, Chapada Vale do Rio Itaim \\
\hline Serviços de saúde & Entre Rios e Vale dos Rios Piauí e Itaueira \\
\hline Turismo litorâneo e arqueológico & Cocais, Serra da Capivara, Planície Litorânea \\
\hline Produção de Soja & Tabuleiro do Alto Parnaíba, Chapada das Mangabeiras \\
\hline Cajucultura & Vale do Guaribas \\
\hline Mineração de Opala & Cocais \\
\hline
\end{tabular}

Fonte: Autores com base em Façanha, (2009); Gândara, (2013); Carvalho, (2015); Putrick, (2019); Santos, (2020). 
Research, Society and Development, v. 10, n. 9, e13310917949, 2021

(CC BY 4.0) | ISSN 2525-3409 | DOI: http://dx.doi.org/10.33448/rsd-v10i9.17949

Figura 1: Mapa dos territórios de desenvolvimento.

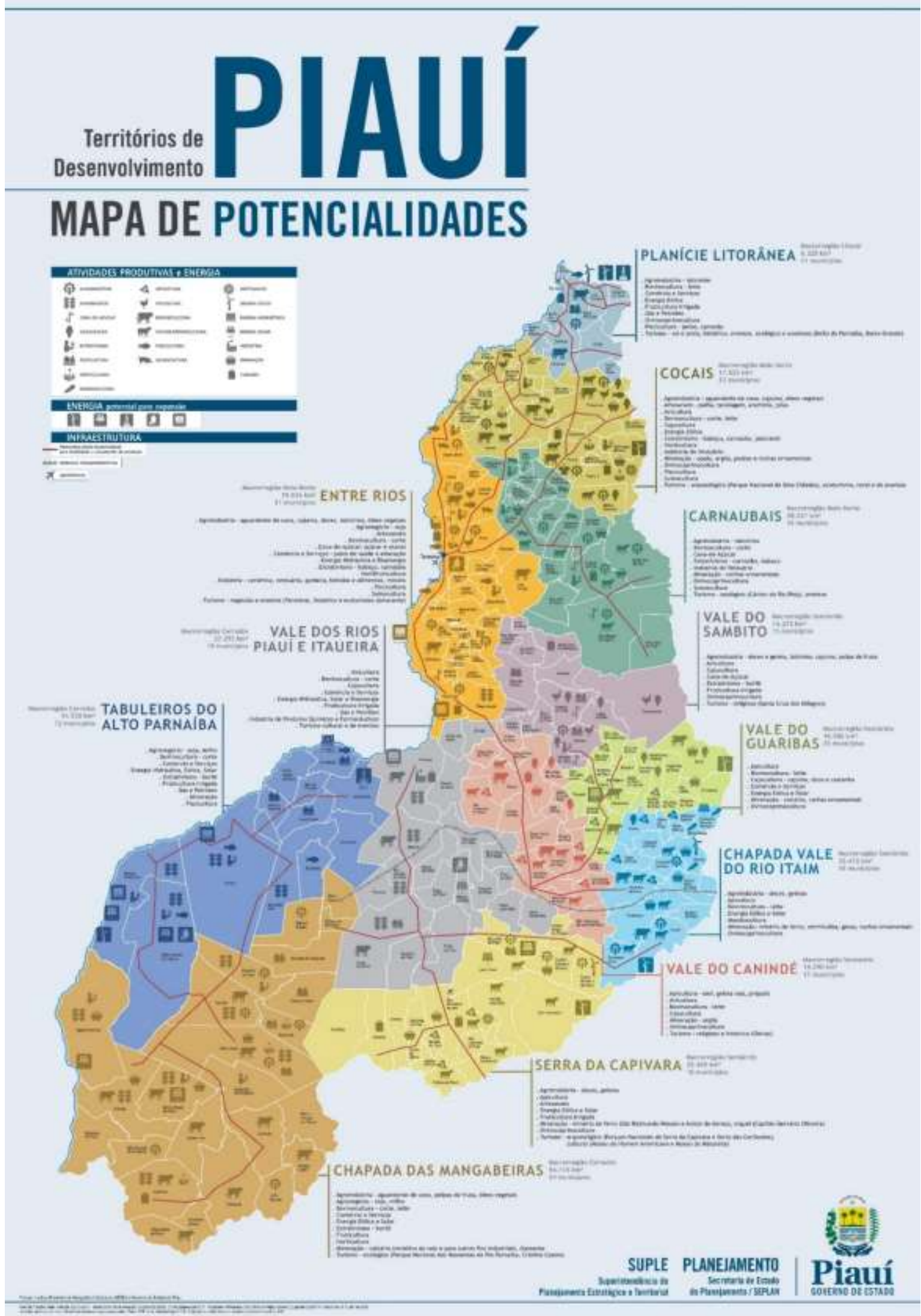

Fonte: SEPLAN (2019). 


\section{Metodologia}

Os procedimentos metodológicos seguem uma abordagem quali-quantitativa de natureza aplicada. Utiliza-se procedimentos bibliográficos e documentais para a realização da pesquisa com objetivos descritivos (Gil, 2008). A plataforma Lens.org (https://www.lens.org/) foi utilizada para investigação das patentes oriundas de Instituições Públicas de Pesquisa do Piauí. As palavras utilizadas para busca foram: Piaui OR Piauí, conforme lógica booleana aplicada na plataforma. Após essa etapa, filtrou-se por depositantes, em que foram encontradas a Universidade Federal do Piauí (UFPI) e o Instituto Federal de Educação, Ciência e Tecnologia do Piauí (IFPI). Com a utilização do Microsoft Excel®, tabulou-se os dados e analisou-se o título e o resumo das patentes, classificando-as em áreas de aplicação com relação com os territórios de desenvolvimento.

Após a coleta de dados de produção de patentes pelas IPP do Piauí, buscou-se trabalhos e documentos que abordassem sobre o desenvolvimento territorial do estado do Piauí. A plataforma Google Acadêmico (https://scholar.google.com.br/) e a Biblioteca Digital Brasileira de Teses e Dissertações (https://bdtd.ibict.br/) foram utilizadas nesse processo. Com isso, selecionou-se trabalhos que formaram o arcabouço teórico utilizado no artigo. Os documentos da Secretaria do Planejamento do Estado do Piauí (SEPLAN) foram empregados no processo metodológico.

No prosseguimento do estudo, elencou-se os territórios de desenvolvimento do Piauí definidos pela SEPLAN e buscou-se na literatura as evidências de atividades com maior relevância econômica no estado, no entanto, não limitando os relacionamentos a isso, expandindo para outras atividades de maior frequência nas regiões descritas no mapa de desenvolvimento territorial da SEPLAN não listadas no referencial consultado.

Utilizou-se documentos relativos ao PIB do Piauí e suas cidades e o plano de desenvolvimento econômico e sustentável para discussão. A literatura e documentação permitiu a análise e relação das informações das patentes com os territórios de desenvolvimento descritos no trabalho. A Figura 2 apresenta um resumo dos procedimentos metodológicos seguidos no artigo.

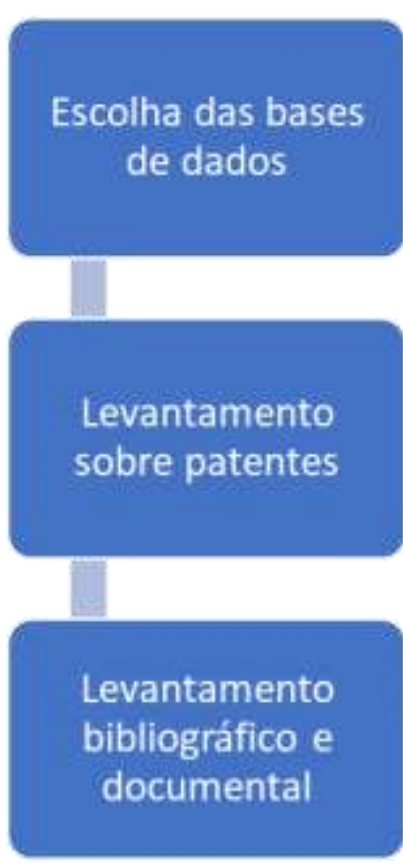

ento

bibliografico e documental
Figura 2: Etapas da metodologia.

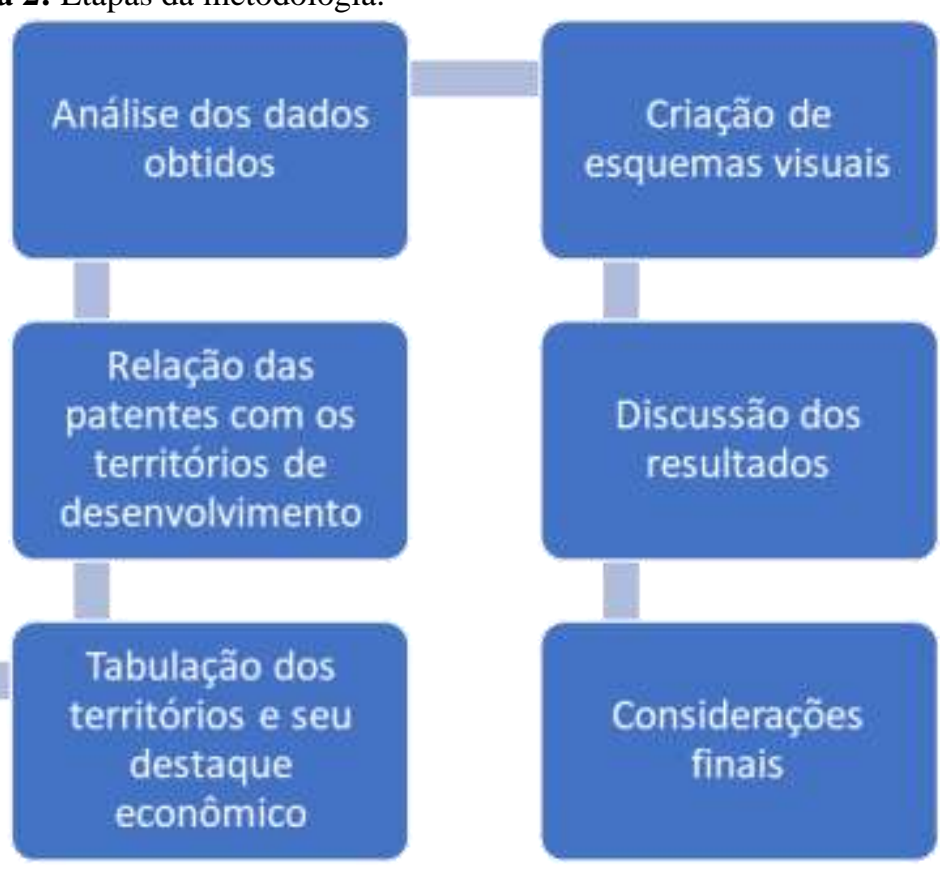

Fonte: Autores (2021). 


\section{Resultados e Discussão}

Os resultados para a consulta de patentes das IPP do Piauí trazem o quantitativo de 98 documentos de patentes encontrados. A UFPI e o IFPI são listados como depositantes das patentes observadas, com intervalo de tempo iniciando em 2010 e finalizando no ano corrente (2021), ressaltando que não houve recorte temporal na consulta. A Figura 3 apresenta os documentos publicados durante os anos encontrados na pesquisa.

Figura 3: Publicação de patentes nos anos.

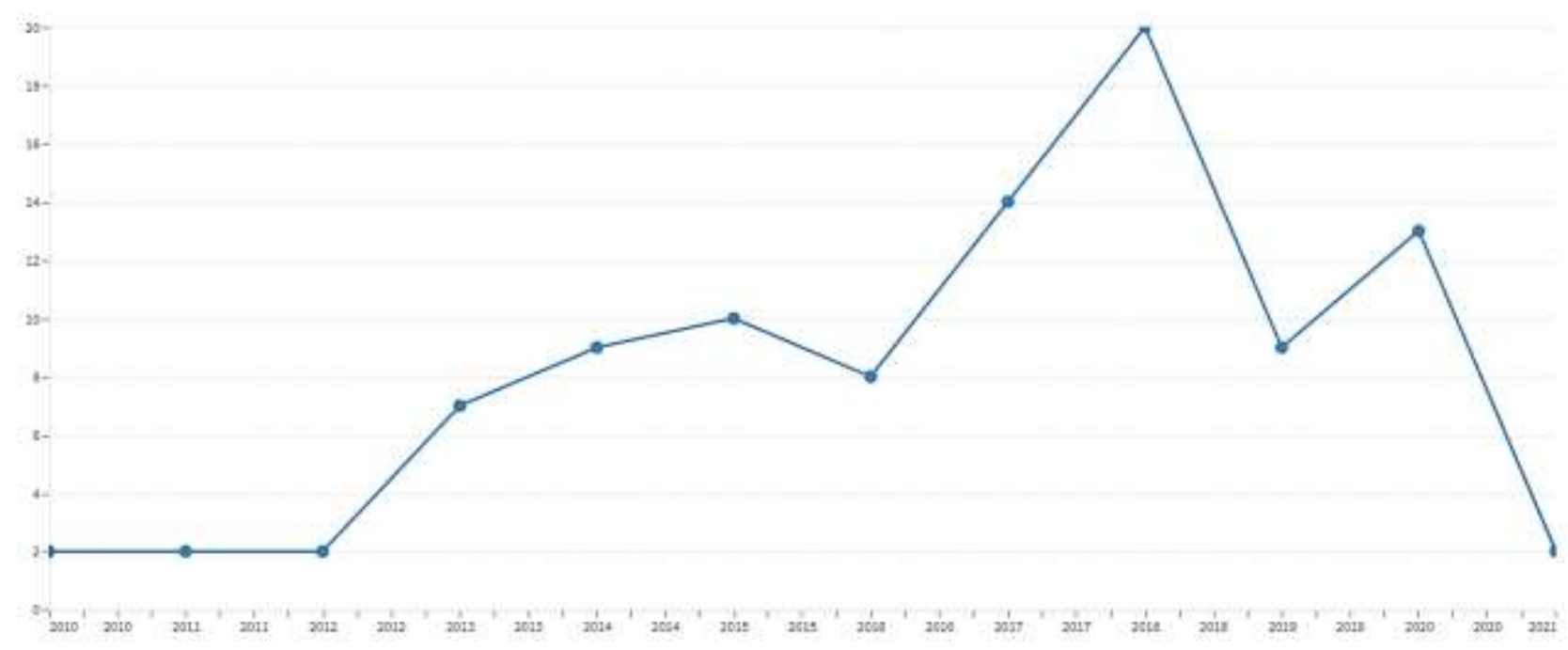

Fonte: Lens (2021).

Observa-se a recente produção de patentes no Piauí, partindo do ano de 2010 até o presente. Ressalta-se que os resultados são condizentes com os dados informados na plataforma Lens.org, ou seja, deve-se confirmar as informações com outras bases de dados, a exemplo, o Instituto Nacional da Propriedade Industrial (INPI). Como não é o objetivo da pesquisa encontrar evidência de temporalidade, concentra-se nas relações propostas.

Das 98 patentes encontradas, após a avaliação dos títulos e resumos, extraíu-se 39 patentes que possuem relações com as vocações econômicas presentes nos territórios de desenvolvimento definidos pela SEPLAN. Em outras palavras, somente 40\%, aproximadamente, das patentes encontradas possuem relação com os territórios de desenvolvimento do Piauí e suas potencialidades. O Quadro 2 ilustra as patentes, seus números e sua relação observada. 
Quadro 2: Patentes com relações econômicas.

\begin{tabular}{|c|c|}
\hline Número da patente & Relação com os potenciais da região \\
\hline BR $102016015020 \mathrm{~A}$ & Agroindustria - Babaçu \\
\hline BR $102018005302 \mathrm{~A}$ & Agroindustria - Babaçu \\
\hline BR $102016022021 \mathrm{~A}$ & Agroindustria - Babaçu \\
\hline BR $102019004253 \mathrm{~A}$ & Agroindústria - Babaçu \\
\hline BR 102014016975 A & Agroindustria - Babaçu, Cajucultura \\
\hline BR $102017001273 \mathrm{~A}$ & Agroindustria - Cajucultura \\
\hline BR 102012021839 A & Agroindustria - Cajucultura \\
\hline BR $102014032181 \mathrm{~A}$ & Agroindustria - Cajucultura \\
\hline BR $102015031366 \mathrm{~A}$ & Agroindustria - Cajucultura \\
\hline BR $102015007200 \mathrm{~A}$ & Agroindustria - Cajucultura \\
\hline BR $102017012139 \mathrm{~A}$ & Agroindustria - Cajucultura; Piscicultura, peixe, camarão \\
\hline BR 102014016979 A & Agroindustria - Cajucultura; Apicultura \\
\hline BR $102017026246 \mathrm{~A}$ & Agroindustria - Cajucultura, babaçu \\
\hline BR PI0803207 A & Agroindustria - Carnaúba \\
\hline BR MU8803020 U & Agroindustria - Carnaúba \\
\hline BR $102014028655 \mathrm{~A}$ & Agroindustria - leite bovino e de cabra \\
\hline BR $102018072253 \mathrm{~A}$ & Agroindústria -Cajucultura, leite, babaçu; Apicultura \\
\hline BR $102012004990 \mathrm{~A}$ & Agroindústria -Cajucultura, babaçu; Apicultura; Mandiocultura \\
\hline BR $102016011344 \mathrm{~A}$ & Apicultura \\
\hline BR $102016011339 \mathrm{~A}$ & Apicultura \\
\hline BR $102016011342 \mathrm{~A}$ & Apicultura \\
\hline BR $102016011348 \mathrm{~A}$ & Apicultura \\
\hline BR $102016011355 \mathrm{~A}$ & Apicultura \\
\hline BR PI1104740 A & Avicultura \\
\hline BR $102017026244 \mathrm{~A}$ & Comércio e Serviços - polos de saúde e educação \\
\hline BR PI1000617 A & Comércio e Serviços - polos de saúde e educação \\
\hline BR $102017028642 \mathrm{~A}$ & Comércio e Serviços - educação \\
\hline BR $102017028641 \mathrm{~A}$ & Comércio e Serviços - educação \\
\hline BR $102018016248 \mathrm{~A}$ & Comércio e Serviços - polos de saúde e educação \\
\hline BR $102015007064 \mathrm{~A}$ & Comércio e Serviços - polos de saúde e educação \\
\hline BR 102015007067 A & Comércio e Serviços - polos de saúde e educação \\
\hline BR $102016019137 \mathrm{~A}$ & Comércio e Serviços - polos de saúde e educação \\
\hline BR $102016019095 \mathrm{~A}$ & Comércio e Serviços - polos de saúde e educação \\
\hline BR 102018005239 A & Extrativismo - buriti \\
\hline BR $102019015986 \mathrm{~A}$ & Mandiocultura \\
\hline BR $102015031370 \mathrm{~A}$ & Ovinocaprinocultura \\
\hline BR $102016011116 \mathrm{~A}$ & Piscicultura \\
\hline BR 102015031367 A & Piscicultura, peixe, camarão \\
\hline BR $102016011110 \mathrm{~A}$ & Piscicultura \\
\hline
\end{tabular}

Fonte: Autores (2021).

Os dados mostraram que soluções com relações com a agroindustria (18 patentes) é muito presente nas patentes piauienses, utilizando produtos de presença marcante na região, como: cajú, castanha, babaçu, carnaúba e leite. Patentes relacionadas com serviços e comércio na área de saúde são frequentes (7 patentes), e para a apicultura (8 patentes). Ovinocultura, bovinocultura, pisicultura, mandiocultura, extrativismo do buriti, educação e avicultura também são vocações econômicas presentes na amostra de patentes piauienses.

$\mathrm{Na}$ literatura consultada é evidenciado o setor do agronegócio de soja como uma vertente econômica relevante, assim como o mercado de minérios de opala. Não evidenciou-se patentes com finalidades para esse setor, sugerindo que há que existem mercados com restrição de patentes como soluções para suas demandas. Em termos de invenções para o turismo arqueológico e litorâneo, não foram evidenciadas inovações para esses segmentos econômicos. Portanto, existem áreas econômicas que carecem de pesquisas para resolução de problemas e geração de produtos inovadores. No entanto, vale 
ressaltar a variedade de setores relacionados cobertos pelas patentes, mesmo que somente 40\%, aproximadamente, tenham relações com as vocações econômicas e territórios de desenvolvimento.

Nessa linha, a Tabela 1 apresenta a contagem de relações entre as patentes e os territórios investigados.

Tabela 1: Contagem das relações das patentes com os territórios.

\begin{tabular}{lr}
\hline Território de Desenvolvimento & Quantidade \\
\hline Cocais & 22 \\
\hline Entre Rios & 22 \\
\hline Vale do Canindé & 19 \\
\hline Vale do Guaribas & 18 \\
\hline Vale do Sambito & 15 \\
\hline Vale dos Rios Piauí e Itaueira & 12 \\
\hline Carnaubais & 12 \\
\hline Chapada Vale do Rio Itaim & 11 \\
\hline Tabuleiros do Alto Parnaíba & 11 \\
\hline Serra da Capivara & 10 \\
\hline Planície Litorânea & 5 \\
\hline Chapada das Mangabeiras & 3 \\
\hline Total Geral & $\mathbf{1 6 0}$ \\
\hline
\end{tabular}

Fonte: Autores (2021).

O território Cocais e Entre Rios possuem o maior número de interações de vocações econômicas que podem ser potencializadas ou aproveitadas pelas patentes. O territórios Entre Rios explica-se pela capital do Piauí estar inserida no contexto, ou seja, há uma maior concetração de recursos econômicos e humanos na região. O território Cocais possui interações em áreas chaves que aparecem nas patentes, assim como o Vale do Canindé e Guaribas, são elas: Apicultura e Agroindustrias do caju. Esses territórios somam cerca de 50\% das interações com as tecnologias elencadas.

O restante das interações distribuem-se no restante dos territórios, destacando os de menores interações, que são: Chapada das Mangabeiras e Planície Litorânea. As duas regiões citadas são as mais distantes da capital do Piauí, e consequentemente do centro econômico, governamental e distante das IPP com melhores estruturas de pesquisa.

Em média, cada patente abrange 4,1 territórios. Destacam-se as patentes BR 102018072253 A e BR 102014028655 A com abrangência de 11 territórios cada, e a patente BR 102012004990 A com 9 interações e por último a BR 102015031370 A com 8. As quatro patentes listadas possuem abrangência em termos de relação com os territórios em maior quantidade. O Quadro 3 apresenta as patentes e seus títulos.

Quadro 3: Patentes com abrangência nos territórios.

\begin{tabular}{|l|l|}
\hline Número da Patente & Título da Patente \\
\hline BR 102018072253 A & Formulação de barra alimentícia \\
\hline BR 102014028655 A & $\begin{array}{l}\text { Processo para obtenção de queijo tipo chevrotin simbiótico produzido com leite bovino, } \\
\text { de cabra e/ou hibrido }\end{array}$ \\
\hline BR 102012004990 A & $\begin{array}{l}\text { Processo de produção de barra nutritiva tendo como ingredientes derivados da } \\
\text { mandioca, mel, mesocarpo de babaçu, pedúnculo e castanha de caju }\end{array}$ \\
\hline BR 102015031370 A & $\begin{array}{l}\text { Dispositivo móvel e software embarcado em circuito microcontrolador para avaliação } \\
\text { reprodutiva de caprinos }\end{array}$ \\
\hline
\end{tabular}

Fonte: Autores (2021). 
A apicultura mostra-se como um setor de interesse para as IPP, assim como a cajucultura e a utilização do babaçu. Estes mostram-se como relevantes no cenário econômico do Piauí, mas não são os únicos. Segundos dados do PIB e de áreas chave para investimentos no Piaú, os setores de energia eólica e solar mostram-se relevantes economicamente e com crescimentos elevados. Outro setor importante é o setor de mineração e o setor do agronegócio ( Superintendência de Estudos Econômicos e Sociais - CEPRO, 2020).

Como dito anteriormente, não encontrou-se evidencias de patentes voltadas para soja ou milho no estado do Piauí. Conforme Façanha (2009), o Tabuleiro do Alto Parnaíba e a Chapada das Mangabeiras são produtores relevantes em termos de economia e empregos, e possuem por base a produção de soja. Não foi possível encontrar fatos que permitam elucidar se a falta de registros de patentes sejam pela falta de pesquisa ou por dificuldade em proteger as tecnologias e melhorias proporcionadas ao segmento, apontando que novos estudos são necessários para evidenciar os argumentos

Em termos de energia eólica e solar, o Piauí possui grandes usinas que utilizam os recursos descritos, no entanto, não evidenciou-se inovações nos segmentos produzidas pelas IPP do estado (CEPRO, 2020; Diagonal, 2013). A mineração, como exemplo da mineração de Opala, são listadas como potenciais mercados de exploração e não foram evidenciados dentro das patentes relação com esses setores (CEPRO, 2020; Diagonal, 2013). Os motivos são desconhecidos e cabe-se a implementação de novas investigações.

Um fato que chama a atenção é que o setor farmacêutico ( 25 patentes) e biotecnológico (12 patentes) possuem presença constante nas patentes que não possuem relação com os setores de vocação econômica e de relação territorial. Uma possível causa seja que o número de cursos de Pós-Graduação em nível de mestrado e doutorado nas áreas descritas influênciam no número de patentes, indicando que os pesquisadores dessa área demonstram interesse na proteção de suas Propriedades Intelectuais, reflexo do número de patentes observadas, embora utilizem recursos que podem não ser abundantes no estado, devido à não relação com as vocações econômicas. Ressalta-se que a Industria Farmacêutica para produção de medicamentos em larga escala é pouco evidente no estado do Piauí, possuindo poucos atores relevantes no setor (Freitas et al., 2020).

Por fim, em termos de resultados, o Quadro 4 ilustra a relação das patentes com os territórios a que possuem relação e a quais podem influenciar positivamente caso sejam exploradas economicamente e atinjam os arranjos produtivos e sociais.

Quadro 4: Patentes e suas relações territoriais.

\begin{tabular}{|l|l|}
\hline Número da patente & Território de desenvolvimento relacionado \\
\hline BR 102016015020 A & Cocais, Carnaubais, Entre Rios \\
\hline BR 102018005302 A & Cocais, Carnaubais, Entre Rios \\
\hline BR 102016022021 A & Cocais, Carnaubais, Entre Rios \\
\hline BR 102019004253 A & Cocais, Carnaubais, Entre Rios \\
\hline BR 102014016975 A & $\begin{array}{l}\text { Cocais, Carnaubais, Entre Rios, Vale do Sambito, Vale do Guaribas, Vale dos Rios Piauí e Itaueira, } \\
\text { Vale do Canindé }\end{array}$ \\
\hline BR 102017001273 A & Cocais, Vale do Sambito, Vale do Guaribas, Vale dos Rios Piauí e Itaueira, Vale do Canindé \\
\hline BR 102012021839 A & Cocais, Vale do Sambito, Vale do Guaribas, Vale dos Rios Piauí e Itaueira, Vale do Canindé \\
\hline BR 102014032181 A & Cocais, Vale do Sambito, Vale do Guaribas, Vale dos Rios Piauí e Itaueira, Vale do Canindé \\
\hline BR 102015031366 A & Cocais, Vale do Sambito, Vale do Guaribas, Vale dos Rios Piauí e Itaueira, Vale do Canindé \\
\hline BR 102015007200 A & Cocais, Vale do Sambito, Vale do Guaribas, Vale dos Rios Piauí e Itaueira, Vale do Canindé \\
\hline BR 102017012139 A & $\begin{array}{l}\text { Cocais, Vale do Sambito, Vale do Guaribas, Vale dos Rios Piauí e Itaueira, Vale do Canindé, Planície } \\
\text { Litorânea }\end{array}$ \\
\hline BR 102014016979 A & $\begin{array}{l}\text { Cocais, Vale do Sambito, Vale do Guaribas, Vale dos Rios Piauí e Itaueira, Vale do Canindé, Chapada } \\
\text { Vale do Rio Itaim, Serra da Capivara }\end{array}$ \\
\hline BR 102017026246 A & $\begin{array}{l}\text { Cocais, Carnaubais, Entre Rios, Vale do Sambito, Vale do Guaribas, Vale dos Rios Piauí e Itaueira, } \\
\text { Vale do Canindé }\end{array}$ \\
\hline
\end{tabular}




\begin{tabular}{|c|c|}
\hline BR PI0803207 A & Cocais, Carnaubais, Entre Rios \\
\hline BR MU8803020 U & Cocais, Carnaubais, Entre Rios \\
\hline BR $102014028655 \mathrm{~A}$ & $\begin{array}{l}\text { Planície Litorânea, Cocais, Carnaubais, Entre Rios, Valo do Sambito, Vale do Guaribas, Chapada Vale } \\
\text { do Rio Itaim, Tabuleiros do Alto Parnaíba, Vale do Canindé, Serra da Capivara, Chapada das } \\
\text { Mangabeiras }\end{array}$ \\
\hline BR $102018072253 \mathrm{~A}$ & $\begin{array}{l}\text { Cocais, Carnaubais, Entre Rios, Chapada Vale do Rio Itaim, Serra da Capivara, Vale do Guaribas, Vale } \\
\text { do Canindé, Vale do Sambito, Vale dos Rios Piauí e Itaueira, Planície Litorânea, Chapada das } \\
\text { Mangabeiras }\end{array}$ \\
\hline BR $102012004990 \mathrm{~A}$ & $\begin{array}{l}\text { Cocais, Carnaubais, Entre Rios, Serra da Capivara, Vale do Guaribas, Vale do Canindé, Vale do } \\
\text { Sambito, Vale dos Rios Piauí e Itaueira, Chapada Vale do Rio Itaim }\end{array}$ \\
\hline BR 102016011344 A & Chapada Vale do Rio Itaim, Serra da Capivara, Vale do Guaribas, Vale do Canindé \\
\hline BR 102016011339 A & Chapada Vale do Rio Itaim, Serra da Capivara, Vale do Guaribas, Vale do Canindé \\
\hline BR $102016011342 \mathrm{~A}$ & Chapada Vale do Rio Itaim, Serra da Capivara, Vale do Guaribas, Vale do Canindé \\
\hline BR $102016011348 \mathrm{~A}$ & Chapada Vale do Rio Itaim, Serra da Capivara, Vale do Guaribas, Vale do Canindé \\
\hline BR $102016011355 \mathrm{~A}$ & Chapada Vale do Rio Itaim, Serra da Capivara, Vale do Guaribas, Vale do Canindé \\
\hline BR PI1104740 A & Cocais, Vale do Sambito, Vale dos Rios Piauí e Itaueira, Vale do Canindé \\
\hline BR $102017026244 \mathrm{~A}$ & Entre Rios, Tabuleiros do Alto Parnaíba \\
\hline BR PI1000617 A & Entre Rios, Tabuleiros do Alto Parnaíba \\
\hline BR $102017028642 \mathrm{~A}$ & Entre Rios \\
\hline BR $102017028641 \mathrm{~A}$ & Entre Rios \\
\hline BR $102018016248 \mathrm{~A}$ & Entre Rios, Tabuleiros do Alto Parnaíba \\
\hline BR 102015007064 A & Entre Rios, Tabuleiros do Alto Parnaíba \\
\hline BR $102015007067 \mathrm{~A}$ & Entre Rios, Tabuleiros do Alto Parnaíba \\
\hline BR 102016019137 A & Entre Rios, Tabuleiros do Alto Parnaíba \\
\hline BR $102016019095 \mathrm{~A}$ & Entre Rios, Tabuleiros do Alto Parnaíba \\
\hline BR 102018005239 A & Vale do Sambito, Tabuleiros do Alto Parnaíba, Chapada das Mangabeiras \\
\hline BR $102019015986 \mathrm{~A}$ & Chapada Vale do Rio Itaim \\
\hline BR $102015031370 \mathrm{~A}$ & $\begin{array}{l}\text { Planície Litorânea, Cocais, Carnaubais, Vale do Sambito, Vale do Guaribas, Chapada Vale do Rio } \\
\text { Itaim, Vale do Canindé, Serra da Capivara }\end{array}$ \\
\hline BR 102016011116 A & Cocais, Entre Rios, Tabuleiros do Alto Parnaíba \\
\hline BR 102015031367 A & Planície Litorânea \\
\hline BR $102016011110 \mathrm{~A}$ & Cocais, Entre Rios, Tabuleiros do Alto Parnaíba \\
\hline
\end{tabular}

Fonte: Autores (2021).

A lista disponível no quandro 4 demonstra como as patentes podem influenciar dentro do modelo econômico de um estado. No entanto, para que isso seja notado é necessário que essas patentes sejam aproveitadas pelos arranjos produtivos e sociais. Esse aproveitamento pode ser por meio de produtos, por meio de empregos, por meio de negociações, e que, embora figurem de diferentes formas, o ponto em comum são os procedimentos de Transferência de Tecnologias que precisam ser executados pelas IPP (Xavier, Freitas, Fabris, Oliveira Junior, 2020). Em perspectiva, salienta-se a necessidade da produção de tecnologias que visem o mercado regional para que o desenvolvimento possa ser influenciado.

Para ilustrar a relação de patentes com os territórios de desenvolviemento, elaborou-se um mapa (Figura 4) com os territórios e a quantidade de patentes relacionadas com suas espacialidades. Com o mapa vizualiza-se o que foi aqui discutido em termos de espacialidades das patentes que possuem relação de vínculo com o desenvolvimento territorial. Vale ressaltar o número de relações com a região do semiárido piauiense que soma-se 85, representado pelos territórios Vale do Sambito, Vale do Guaribas, Chapada Vale do Rio Itaim, Vale do Canindé, Vale dos Rios Itaueira e Piauí, e Serra da Capivara, possuindo o 
maior número nesse critério. Entende-se que a região possui potencial para desenvolvimento de tecnologias endógenas e que busquem a melhoria de vida para as condições climáticas da região.

Figura 4: Mapa das patentes e suas relações de desenvolvimento territoriais.

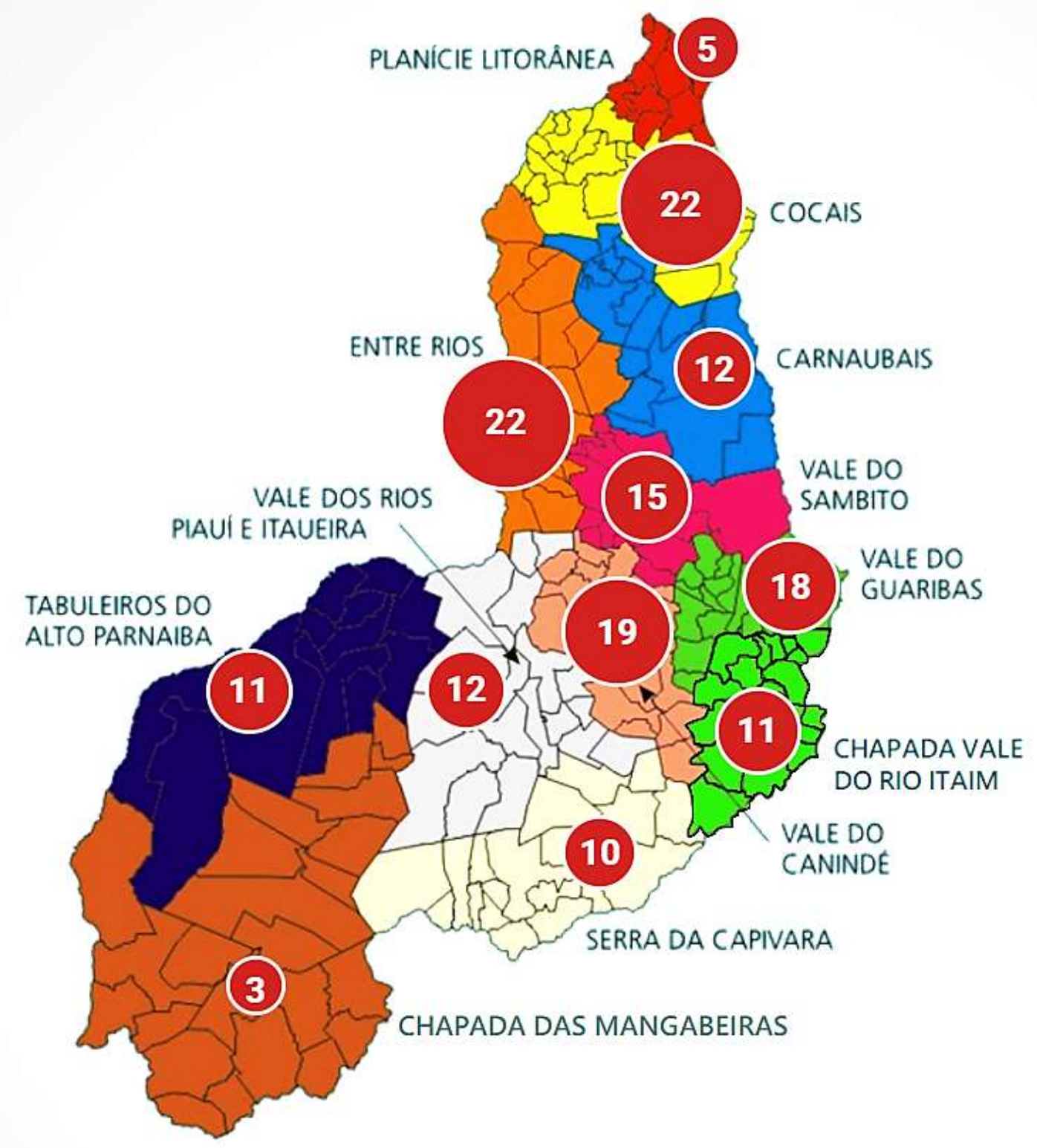

Fonte: Autores (2021).

\section{Considerações Finais}

O estudo teve por finalidade relacionar as patentes e os territórios de desenvolvimento descritos pela Secretaria de Planejamento do Estado do Piauí. Evidencia-se que é necessário estabelecer relações mais fortes entre essas entidades abstratas para que se concretizem as relações reais de negócios dentro das vocações regionais. Acredita-se que com o fortalecimento as patentes podem alavancar tanto a produção de tecnologias para a sociedade quanto os empregos gerados no processo.

Em termos de análise, não buscou-se avaliar as vocações do povo piauiense como um mercado consumidor, mas sim em termos de capacidade de interação produtiva, de negócio e de ampliação econômica. Ou seja, promover essas interações pode trazer as tecnologias em formas de produtos ou soluções que tenham participação nos arranjos sociais e produtivos locais. 
Encontrou-se um número relevante de patentes que possuem relações com a indústria, principalmente a indústria farmacêutica e de biotecnologia. Como estas não foram evidenciadas como relacionadas com as vocações do estado, foram descartadas da análise, no entanto por terem números relevantes, são mercados que podem ser estudados em termos de proveito. Recomenda-se que os pesquisadores utilizem-se dos processos de proteção de tecnologias para que seja possível a progressão para a Transferência de Tecnologia (TT) (Garnica, 2006; Brito e Fausto, 2015; Soares, 2018; De Almeida, 2019; De Oliveira Junior e De Almeida, 2019; Freitas et al, 2020), e recomenda-se também que as IPP possam: promover editais e fomentos para solução de problemas sociais relacionados com as demandas do seu entorno; promovam pesquisas e fomentos com empresas parceiras para facilitação de uma TT e fomentem aos pesquisadores a motivação para executarem pesquisas relacionadas com os territórios de desenvolvimento do seu entorno.

Em termos de espacialidade, verificou-se que os territórios com maiores quantidades de patentes registradas possuem estreitas ligações com seus arranjos produtivos locais, suas dinâmicas econômicas e contingentes populacionais - Cocais e Entre Rios (22 cada um). Registra-se, também, que a região semiárida piauiense também possui números consideráveis de registros na temporalidade em exame, representada pelo território Vale do Canindé (19 patentes) e Vale do Guaribas (18 patentes). Entretanto, o território de maior produtividade agrícola do estado - Tabuleiros do Alto Parnaíba, evidencia pouca quantidade registrada (11 patentes), dado que revela-se necessário pesquisas e inovações endêmicas, uma vez que se clareia uso de tecnologias já desenvolvidas. Por fim, nota-se que as espacialidades não possuem uniformidade estatística de distribuição de suas pesquisas, cabendo estratégias para ampliação de áreas pouco cobertas com desenvolvimento tecnológico, mas que possuem relevância produtiva e social.

Ademais, dada a amplitude da temática, sugere-se, dentre outros nortes de pesquisas, que se examine de forma mais pormenorizada os impactos da aplicabilidade das patentes de inovações tecnológicas nos territórios de desenvolvimento e suas nuances com a melhoria das condições de vida de seus habitantes, em especial os ligados a geração de emprego e renda a partir dessas criações, bem como ao dinamismo por elas desencadeadas nos arranjos produtivos locais. Para ampliação do entendimento, tem-se a investigação de Propriedades Intelectuais, além das patentes, como perspectivas futuras.

\section{Referências}

Brito, E. V., \& Fausto, D. A. (2015). Critérios utilizados por universidades públicas para o abandono de patentes e de pedidos de patentes não licenciados. Revista iPecege, 1(2), 147-168.

Carvalho, C. A. D. (2015). O papel do APL da opala de Pedro II, Piauí, na estruturação do turismo mineral do município (Doctoral dissertation, Universidade de São Paulo).

De Almeida, J. J. M. (2019) A Perspectiva Estratégica e Operacional da Propriedade Intelectual da Universidade Federal De Sergipe: Proposta de um Modelo Conceitual. Dissertação (Mestrado em Ciência da Propriedade Intelectual) - Universidade Federal de Sergipe, São Cristóvão - SE.

De Oliveira Júnior, A. M., \& de Almeida, J. J. M. (2019). Análise das inter-relações das patentes das universidades sob a perspectiva de mercado. Navus: Revista de Gestão e Tecnologia, 9(4), 139-160.

Decreto n. 5.154, de 23 de julho de 2004 (2004). Regulamenta o parágrafo $2^{\circ}$ do art. 36 e os arts. 39 a 41 da Lei nº 9.394 , de 20 de dezembro de 1996. Diário Oficial da União, Brasília.

Decreto n. ${ }^{\circ}$ 2.207, de 15 de abril de 1997 (1997). Regulamenta, para o Sistema Federal de Ensino, as disposições contidas nos arts. 19, $20,45,46$ e $§ 1^{\circ}, 52$, parágrafo único, 54 e 88 da Lei n. 9394, de 20 de dezembro de 1996, e dá outras providências. Diário Oficial da República Federativa do Brasil, Brasília, p. 7534 .

Diagonal Transformação de Territórios, 2013. Plano De Desenvolvimento Econômico Sustentável Do Piauí (PIAUÍ 2050). Piauí. http://www.cepro.pi.gov.br/download/201608/CEPRO02_9b568b361f.pdf

Façanha, A. C. (2009). Desenvolvimento territorial recente em espaços sub-regionais dinâmicos no Piauí. Tese de Doutorado. Universidade Federal de Pernambuco. Recife.

Freitas, R. A. B. de, De Oliveira Júnior, A. M., Melo, H. C. S., Azevedo, M. A. F., Bezerra da Silva, M., \& Camargo, M. E. (2020a). Public Research Institutions and Their Connections with Patents of Companies in Technological and Regional Development. International Journal for Innovation Education and Research, 8(5), 95-108. https://doi.org/10.31686/ijier.vol8.iss5.2315 
Research, Society and Development, v. 10, n. 9, e13310917949, 2021

(CC BY 4.0) | ISSN 2525-3409 | DOI: http://dx.doi.org/10.33448/rsd-v10i9.17949

Gândara, F. C. (2013). Dinâmica no uso da terra de 1991 a 2010 da região semiárida do estado do Piauí: cajucultura e apicultura. Tese de Doutorado. Universidade Estadual Paulista. Jaboticabal.

Garcia, J. C. R. (2006). Os paradoxos da patente. DataGramaZero-Revista de Ciência da Informação, 7(5).

Gil, A. C. (2008). Métodos e técnicas de pesquisa social. (6a ed.), Ediitora Atlas SA.

Lei $n^{\circ}$. 11.892, de 29 de dezembro de 2008 (2008). Institui a Rede Federal de Educação Profissional, Científica e Tecnológica, cria os Institutos Federais de Educação, Ciência e Tecnologia, e dá outras providências. Diário Oficial da União, Brasília.

LENS.ORG. [Base de dados - Internet]. (2020). Cambia, Queensland University of Technology. https://www.lens.org/.

Lei no 10.973, de 2 de dezembro de 2004 (2004). Dispõe sobre incentivos à inovação e à pesquisa científica e tecnológica no ambiente produtivo e dá outras providências. Brasília.

Lei no 9.394, de 20 de dezembro de 1996 (1996). Estabelece Diretrizes e Bases da Educação Nacional. Brasília.

Livesey, F. (2014). Report on survey of Brazilian Technology Transfer Offices (TTOs) June 2014.

Ministério da Ciência, Tecnologia e Inovação, (2019). Formulário de Informações sobre a Política de Propriedade Intelectual das Instituições Científicas e Tecnológicas. Secretaria de Desenvolvimento Tecnológico e Inovação. Política de Propriedade Intelectual das Instituições Científicas e Tecnológicas do Brasil: Relatório Formict 2018.

Putrick, S. C. (2019). O turismo na rota das emoções e no desenvolvimento socioeconômico de municípios do estado do Piauí. Tese de Doutorado. Universidade Federal do Paraná. Curitiba.

Santos, W. B. D. (2020). A dinâmica urbanorregional de Floriano (PI) conforme os estabelecimentos prestadores de serviços de saúde (Master's thesis, Universidade Federal do Rio Grande do Norte).

Secretaria de Planejamento do Estado do Piauí - SEPLAN (2019). Mapa dos territórios de desenvolvimento. Teresina - PI. http://www.seplan.pi.gov.br/mapa_abril19.pdf Acesso em julho de 2021.

Soares, D. S. C. (2018). Modelo híbrido de avaliação e valoração de tecnologias Desenvolvidas em universidades. Dissertação (Mestrado em Ciência da Propriedade Intelectual) - Universidade Federal de Sergipe, São Cristóvão - SE.

Superintendência de Estudos Econômicos e Sociais - CEPRO, 2020. PIB dos municípios 2018. Teresina. http://www.seplan.pi.gov. br/download/202012/SEP18_fcbc2225ec.pdf

Xavier, A. C. G., Freitas, R. A. B. de, Fabris, J. P., \& Oliveira Junior, A. M. de (2020). Transferências de Tecnologias das Universidades para Empresas, Análise das Patentes de Terras Raras. BackUp Books. 